\title{
Student Community Project to Design a Mini-golf Project for the City of Leesville, LA
}

Dr. Mohammed Benalla MB, Vaughn College of Aeronautics \& Technology 


\title{
Student Community Project to Design of a Mini Golf Course for Leesville City - LA
}

\author{
Mohammed Benalla, Department of Engineering and Technology \\ Vaughn College, 8601 23rd Ave, East Elmhurst, NY 11369
}

\begin{abstract}
This paper described a community project to design a first draft of a mini golf course, 18 holes, with a future location in the city of Leesville, LA. The course was designed to be challenging, aesthetically pleasing and incorporating themes that reflected the history and culture of the city in order to promote sightseeing and create a better area for the locals to enjoy time and have fun. The project was designed by students from Engineering Technology, ET, and Creative \& Performing Arts, CPA, Departments. Groupmates from both departments operated closely under the supervision of two faculties from ET and CPA to produce a design proposal along with graphic illustrations that highlighted various themes related to the historical and cultural aspect of the city. The design started with a hand sketch that was modified to fit the course area; then, an architectural illustration was accomplished using AutoCAD. The theme of the mini golf course illustrated the most important momentum in the civil and cultural history of the city such: No Man's Land, Railroad, Timber Boom and Fort Polk.

Students from both areas of engineering and graphic design were able to apply their knowledge by using different software to develop the project, and submitting the final presentation which included both technical and emblematical illustrations.
\end{abstract}




\section{I- Introduction}

Leesville is a small city of Vernon Parish, Louisiana. Including the fort Polk installation, the population of the city overpasses 20,000 based on the 2010 United State Census. The region is famous of the four themes, Timber Boom, Railroad, No Man's Land and Fort Polk ${ }^{1}$.

In Fall 2016, the mayor's office in Leesville contacted the Department of Engineering Technology in Northwestern State University (NSU) to design an eighteen-hole mini-golf project (DMGP).

Two NSU senior students from the Engineering Technology Department, ET, accepted to work on the community project. Both students had a deep understanding of the architectural drafting and a good familiarization with the software design AutoCAD.

Further discussions with the mayor office identified the need to incorporate different themes that reflect the historical and cultural aspect of the region and the State of Louisiana. The themes are:

1- No Man's Land,

2- Fort Polk

3- Timber Boom

4- Railroad.

Based on these new requirements, three more students from the Creative \& Performing Arts Department, CPA, joined the DMGP in order to offer an authentic visual solution to the architectural design by graphically implementing the four historical themes of the city.

The realization of the project went through four major steps. The first step was related to the familiarization and understanding of the project. During this phase, the students searched online and downloaded different papers on the subject. The collected papers were exchanged, discussed and summarized. In parallel with the online search, the students visited few mini golf courses in the adjacent cities, Alexandria and Shreveport. In the second step, the study and the examination of the project location from geometrical and topological sideways was effectuated to allow the drawing of the architectural design on the third step. At the end, the CPA students incorporated to the architectural design the five themes that reflect the history and the culture of the region.

In this project the students learned how to discuss, analyze and design a community project, how to set the objectives and place the time frame with work breakdown structure in order to properly realize the project. They also learned how to coordinate between each other and how to improve their self-learning and creativity skills. More than that, the students learned how to work effectively under the supervision of two professors from different departments, ET and CPA. At the end, this project represented a good opportunity for the students to apply their academic knowledge on a real life project.

\section{II- Step 1: Study of the project}

During this phase, the students deepened their knowledge and familiarization with the mini golf course features using online investigation and visiting different mini golf courses in Shreveport 
and Alexandria cities. The online investigation included the review of different mini golf project studies $2,3,4,5$. This period started with the month of November and lasted until the beginning of the following spring semester. During this process the students learned different mathematical skills related to the design of the mini golf course notably geometry strand and trigonometry formula to calculate the distance between the wholes and the settings of obstacles. Concerning geometry strand the students learned the specificities of the different shapes such as triangles, polygons and circles along with their three dimensional representations; while, for trigonometry they learned the details of how to locate the holes and how to settle the difficulties and obstacles in between based on the angles of incidence and reflection. The students learned also how to make some holes more or less challenging depending on the degree of alignment of the holes and the size of obstacles in the middle. Generally, this project represented good mathematical and geometrical modeling process with a direct application on real word problem. During this period the student refreshed their familiarization with AutoCAD software that they learned few semesters ago.

\section{III- Step 2: Sketch and drawing of the architectural design}

The second part of this project started in the beginning of the spring 2017. During this period students sketched a first draft of the architectural design based on the dimension and the size of the location. The sketch was designed based on different norms. First, the total rectangular area of the course was accurately measured and divided to twelve equal rectangles. Second, the distribution of the holes as well as the difficulties and obstacles were located depending on random criterions. Third, the degree of challenges was gradually increased from the beginning to the end of the course and the part for the disabled people was planned with all the required facilities and included in the middle of the course with less challenges.

In order to include all the themes, the rectangular shape of the course was divided to four parts, No Man's Land, Fort Polk, Timber Boom and Railroad themes. Flexibility in adjusting and properly locating the holes and the obstacles were left to the final draft after the mayor office accepted the first draft of the proposal.

Once the architectural draft was sketched and accepted, the engineering students redrew the mini golf sketching on AutoCAD, Figure 1. 


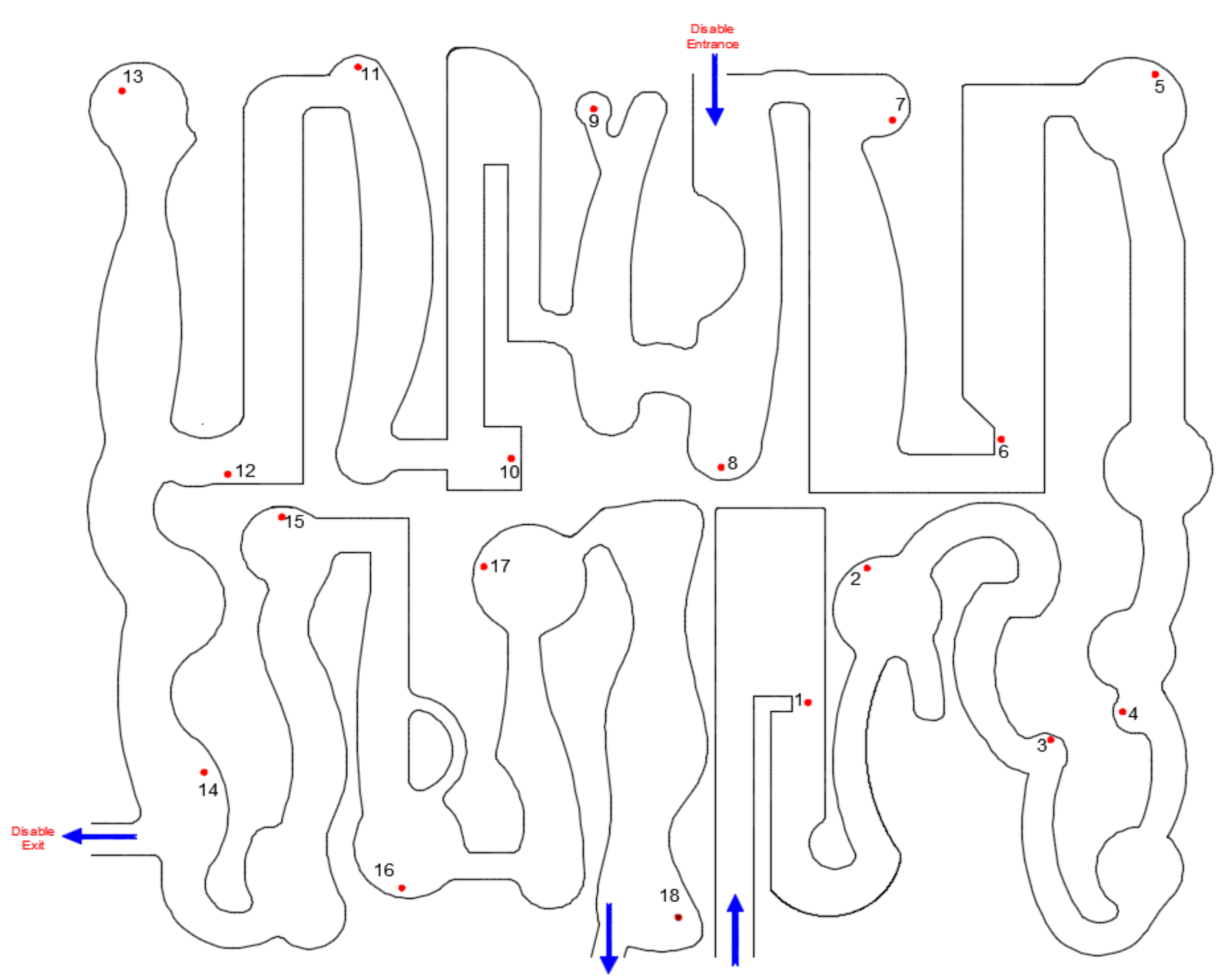

Figure 1. Architectural design of the mini golf project 


\section{IV- Step 3: Illustration of the four themes on the architectural drawing}

\begin{tabular}{|l|l|}
\hline TIMBER BOOM & RAILROAD \\
\hline FORT POLK & NO MAN'S LAND \\
\hline
\end{tabular}

Figure 2. The distribution of the four themes on the site of the golf

The rectangular shape of the site for the mini golf course was divided to four equally parts, Figure 2. Each part incorporated one of the four themes. The design of the course with the four themes depicted the culture and history of the city and the state. The subdivisions of the area includes: 1. No Man's Land; 2. Fort Polk; 3. Timber Boom; 4. Railroad. Adobe Illustrator and Adobe Photoshop soft wares were utilized to create the illustrations. The art students adopted an illustration of grid system in order to bitterly visualize the sight. Adobe Illustrator allowed the production of vector graphics that were scalable as small or large as needed, and the graphics kept their resolution and clarity. Adobe Photoshop with pixel based program was utilized in order to perform the manual illustrations and Wacom tablets were used to produce these illustrations. Photography was another way to convey information for the project; images from the location were fundamental during the research process as students were able to compare their ideas with some other golf courses. Using these technics, students were able to come up with different styles of illustrations to come up with the final proposal.

1- No Man's Land and the neutral ground of Louisiana are expressions that represent the historical dispute of this region between the Spanish Texas and United State during the end of the nineteenth century. The theme related to the No Man's Land was represented on the first part of the rectangle on the lower right quarter, Figure 3.

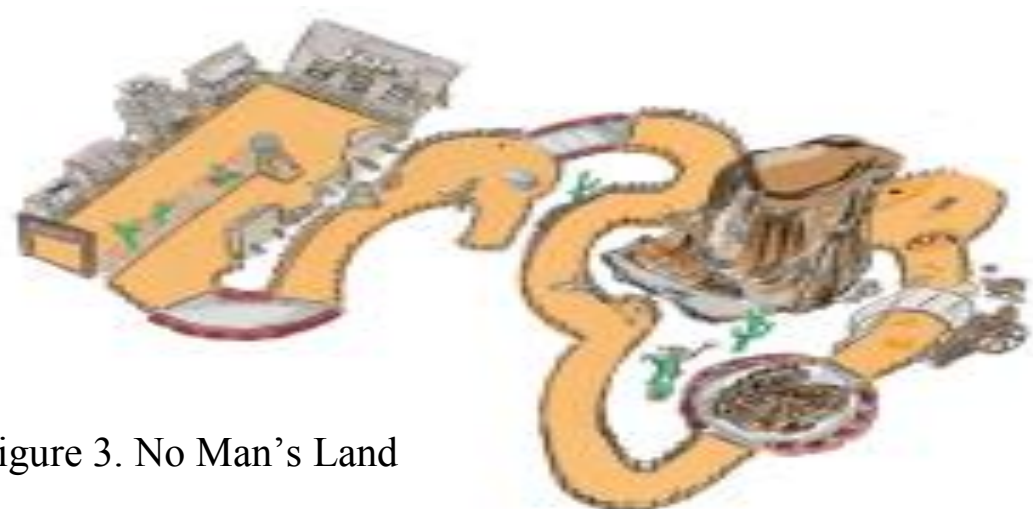


1- Railroad in Louisiana appeared in the beginning of the nineteenth century. The fact that trains operated in this region of the united State that early, made the railroad one of the specificities of Louisiana. The railroad theme was represented on the right upper side of the rectangle, Figure 4.

Figure 4. Railroad

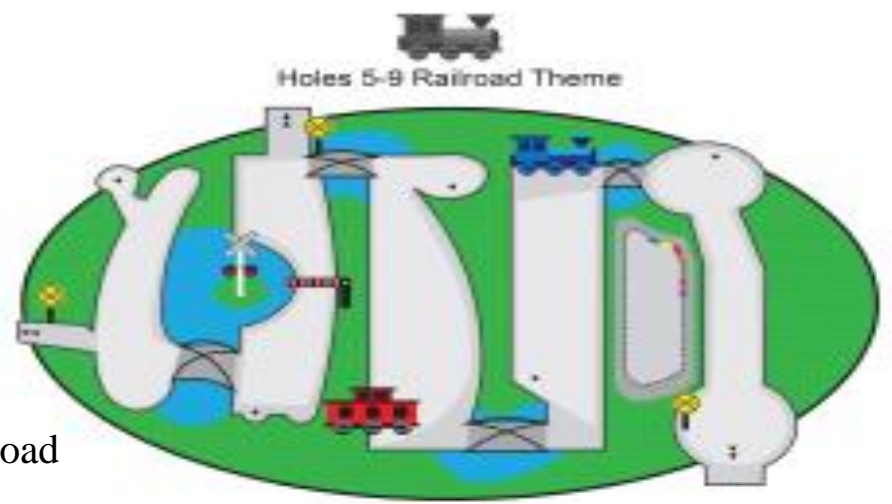

2- Timber Boom theme represents the mills and logging that were confined largely to areas along waterways. The timber boom theme was represented on the left upper side of the site, Figure 4.

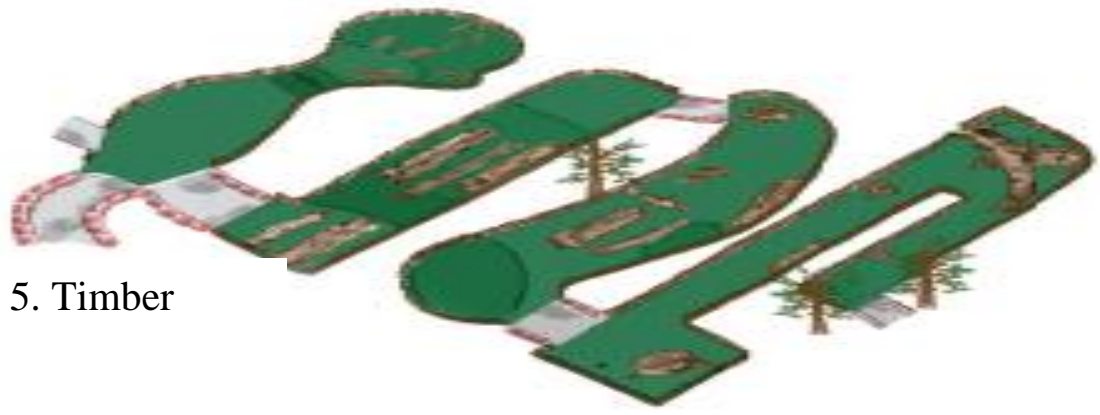

3- Fort Polk is a United States Army installation located ten miles east of Leesville city. The Theme of Fort Polk is incorporated on the last and forth part of the mini-golf location, left lower side, Figure 5.

\section{V- Step 4: Creation of the logo and gathering everything in one poster}

The last component of the project was the logo that was created based on the main golf tools which were incorporated in sand watch, Figure 7.

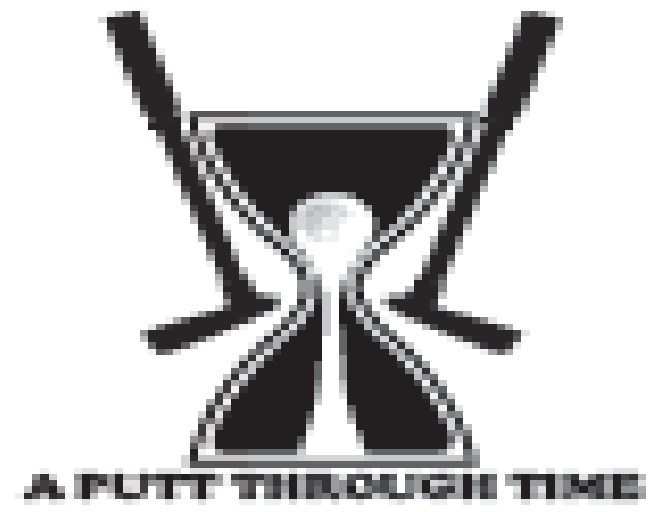

Figure 6. The logo of the mini golf project. 


\section{四 | NORTHWESTERN STATE}

\section{Mini Golf Project}

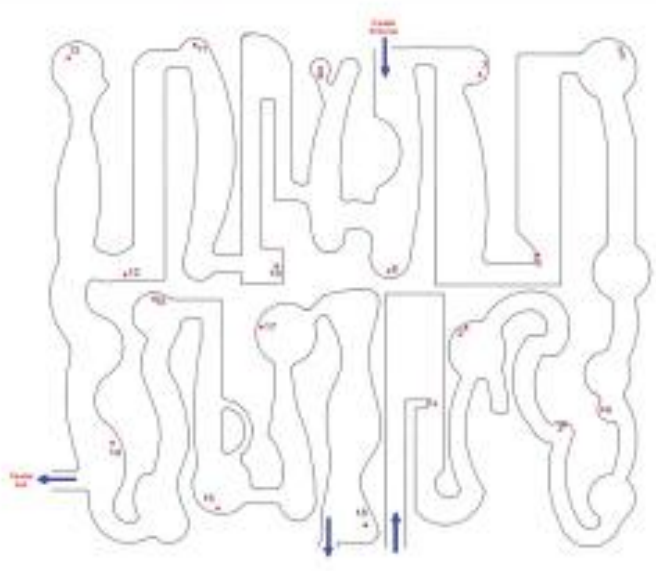

Miniature Golf Plans and Layout

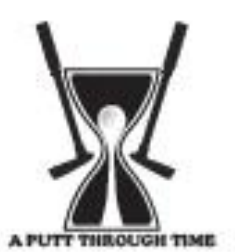

City of Leesville

Project:

Minigolf, Putt Putt Golf

Project design: Spring 2016

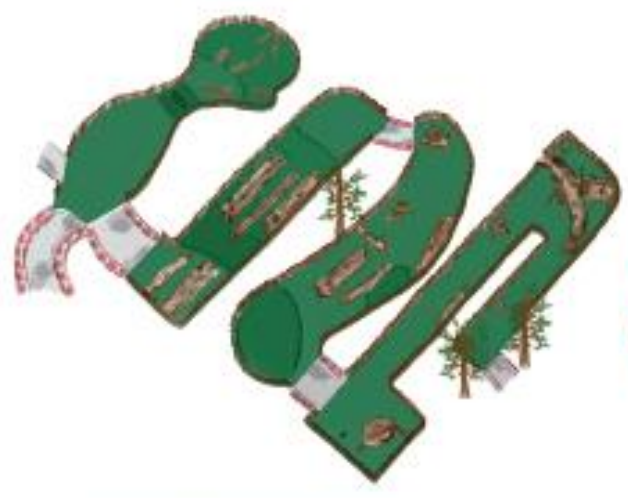

TIMBER BOOM

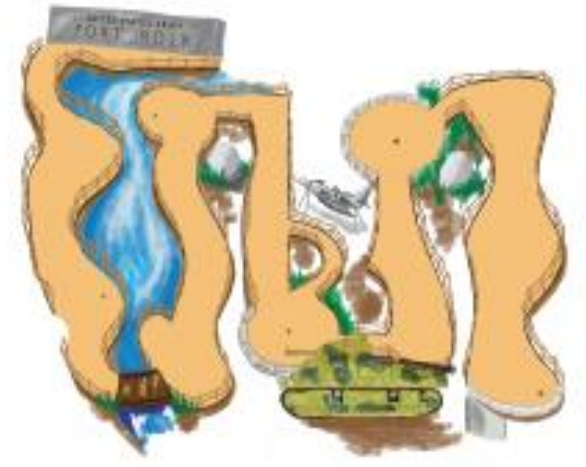

FORT POLK

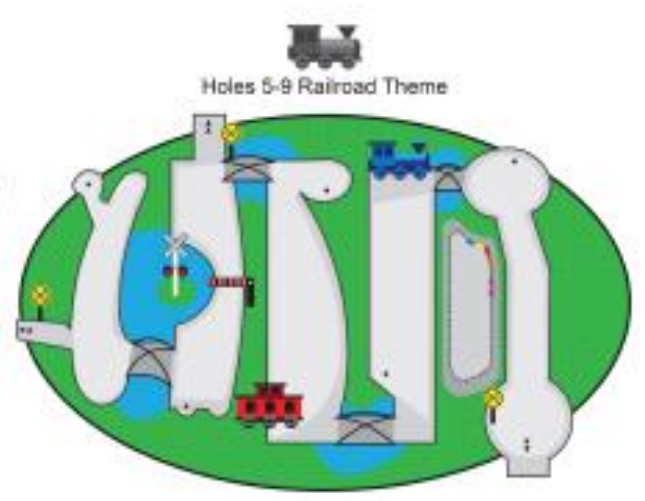

RAILROAD

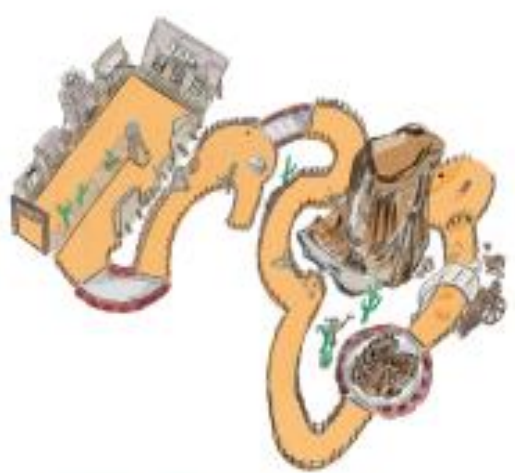

NO MAN'S LAND
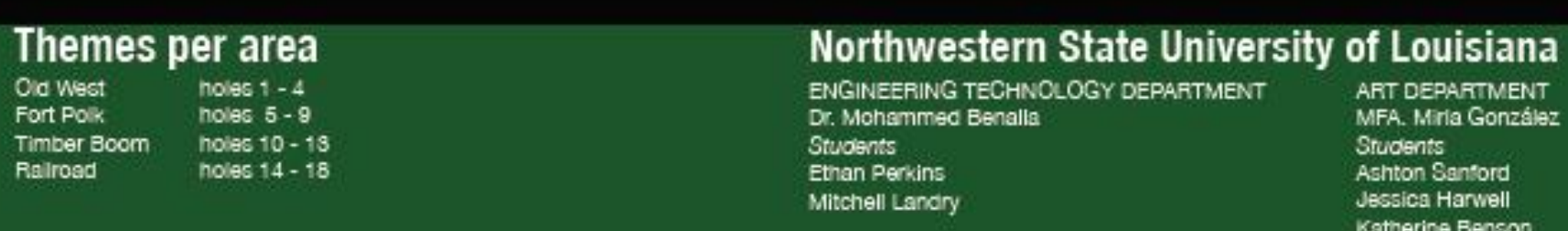

Figure 7. Poster representing the architectural design along with the illustration of the four themes of the city of Leesville 


\section{VI- Conclusion}

The Design of a Mini Golf Course was an interdisciplinary project in which students explored the integration of different disciplines and application of software such as geometry strand, trigonometry, AutoCAD, vector graphics editor Adobe Illustrator and raster graphics editor along with Adobe Photoshop.

Working in an interdisciplinary group from different departments, engineering technology and graphic art, the students developed different skills. These skills were communication, selflearning, flexibility, and team work.

There were different evidences that showed how successful this project was, first, the good relationship that gathered the groupmates during this the project, second, the knowledge that the students exchanged between them from both majors engineering and art, third, the degree of satisfaction and contentment the Mayor's office exhibited when they received the final design of the project to the point that a press release ceremony was organized during the project submission in the presence of the Mayor and the President of NSU, Figure 8. 


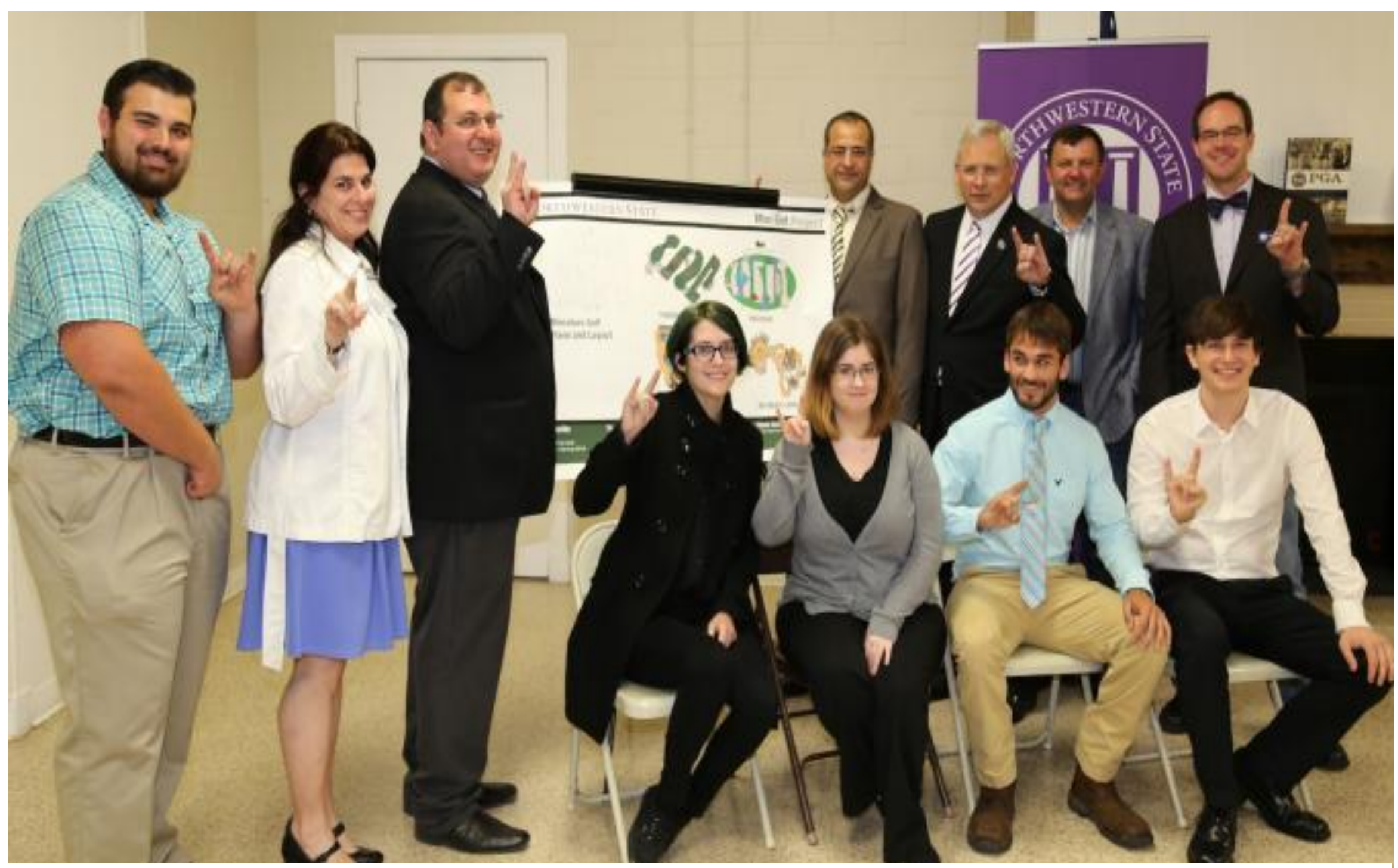

Figure 8. Press release picture between the ET and CPA Departments, NSU in presence of the Mayor of Leesville city, The president of NSU, the head of Both departments, The students along with the two professors that worked on the Project 


\section{References}

1. Louisiana Division of Historic Preservation, Downtown Leesville Historic District Design Guidelines Leesville, Louisiana, April 2012.

2. Meyers, K. Implementation of a Low-Budget, First-Year Engineering Project Based Experience: The Design of a Mini-Golf Hole. ASEE Annual Conference \& Exposition, 2014

3. Bellino, M. Hands-on Activity: Geometry Solutions: Design and Play Mini-Golf. CU Teach Engineering, www.teachengineering.org, 2017

4. Taylor, D. Mars Miniature Golf Design Challenge. Buck Institute for Education. 2008

5. Institute for Human Centered Design. Golf Facilities. www.adachecklist.org. 